\title{
EFEITO DE DOSES DE NITROGÊNIO NA NODULAÇÃO E BIOMASSA DE PLANTAS DE SOJA
}

Nicole Raquel Pinto Cardoso'; Adrianne Braga da Fonseca²; Bruna Sayuri Fujiyama³; Jácio Abreu Ramos²; Mário Lopes da Silva Júnior ${ }^{4}$

${ }^{1}$ Engenheira Agrônoma formada pela Universidade Federal Rural da Amazônia (nicolepcardoso@gmail.com) Belém - Brasil;

${ }^{2}$ Acadêmico(a) do curso de Agronomia pela Universidade Federal Rural da Amazônia;

${ }^{3}$ Mestre em Agronomia - Nutrição Mineral de Plantas pelo PPGAgro UFRA;

${ }^{4}$ Professor Doutor de Nutrição Mineral de Plantas da Universidade Federal Rural da Amazônia.

Recebido em: 06/04/2018 - Aprovado em: 10/06/2018 - Publicado em: 20/06/2018 DOI: 10.18677/EnciBio_2018A40

\begin{abstract}
RESUMO
A cultura da soja é muito exigente em macro e micronutrientes, possuindo altos custos para suplementação mineral. $O$ objetivo deste trabalho foi verificar a influência de diferentes doses de nitrogênio $(N)$ na nodulação, crescimento e acumulo de biomassa de plantas de soja. Foram aplicadas quatro doses de $\mathrm{N}$ (100, 75,50 e $25 \mathrm{mg}$ de $\mathrm{N} / \mathrm{kg}$ de solo), em 5 repetições, totalizando 20 unidades experimentais. As análises foram realizadas aos 22 e 39 dias após emergência (DAE). A quantidade de $\mathrm{N}$ aplicada nas unidades experimentais afetou significativamente a nodulação das plantas, apresentando melhor resultado nos tratamentos de menor dose. O N pouco interferiu na altura e diâmetro do caule, porém as maiores doses aplicadas proporcionaram maior produção de matéria seca da parte área.
\end{abstract}

PALAVRAS-CHAVE: macronutriente, nodulação, nutrição de plantas.

\section{EFFECT OF NITROGEN DOSES ON NODULATION AND BIOMASS OF SOYBEAN PLANTS}

\begin{abstract}
Soybean cultivation is very demanding on macro and micronutrients, with high costs for mineral supplementation. The aim of this work was to verify the influence of different doses of nitrogen $(\mathrm{N})$ on nodulation, growth and biomass accumulation of soybean plants. Four $\mathrm{N}$ doses (100, 75, 50 and $25 \mathrm{mg} \mathrm{N} / \mathrm{kg}$ soil) were applied in 5 replicates, totaling 20 experimental units. The analyzes were performed at 22 and 39 days after emergency (DAE). The amount of $\mathrm{N}$ applied in the experimental units significantly affected the nodulation of the plants, presenting better results in the lower dose treatments. The $\mathrm{N}$ did not interfere in the height and diameter of the stem, however, the higher doses applied gave higher dry matter production of the area.
\end{abstract}

KEYWORDS: macronutrient, nodulation, plant nutrition. 


\section{INTRODUÇÃO}

A soja é uma planta de origem asiática amplamente cultivada no Brasil com o principal objetivo de obter farelo e óleo para utilização na indústria alimentícia e farmacêutica. De acordo com a USDA (2017) os Estados Unidos são o maior produtor mundial de soja com 116,9 milhões de toneladas de grãos na safra 2016/17, seguido pelo Brasil, com 114,1 milhões de toneladas de grãos colhidos na mesma safra.

A produção brasileira de soja ocorre principalmente nas regiões Centro-Sul, Sul e Sudeste do país, sendo que ao longo dos últimos anos notou-se crescimento expressivo nas produções das regiões Norte e Nordeste (SIDRA, 2018). A cultura da soja é muito exigente em macro e micronutrientes, assim, é necessário que os nutrientes essenciais estejam presentes no solo de forma equilibrada, sendo importante dar atenção à práticas como calagem e adubação, as quais podem ser realizadas de forma satisfatória quando embasadas em análise do solo, principalmente, e a análise foliar, como ferramenta complementar (SFREDO, 2008).

De acordo com Cravo et al., (2010) no Manual de Recomendações de Adubação e Calagem para o Estado do Pará indica-se aplicar em média $75 \mathrm{~kg}$ de Pentóxido de Fósforo $\left(\mathrm{P}_{2} \mathrm{O}_{5}\right)$ por ha, e $60 \mathrm{~kg}$ de Óxido de Potássio $\left(\mathrm{K}_{2} \mathrm{O}\right)$ por ha, entretanto é recomendado evitar adubação nitrogenada, pois a mesma inibe a nodulação, porém, caso seja necessário utilizar formulações contendo nitrogênio $(\mathrm{N})$, a aplicação não pode ultrapassar $20 \mathrm{~kg}$ por ha.

O N faz parte de aminoácidos, proteínas, DNA e RNA e apesar de estar presente em elevadas quantidades na atmosfera, animais e plantas não conseguem metabolizá-lo na forma gasosa. Através da fixação do $\mathrm{N}$ atmosférico por bactérias especializadas o $\mathrm{N}$ é transformado em formas assimiláveis para plantas e animais (CABALLERO, 2015).

Atualmente o fosfato monoamônio (MAP) é amplamente utilizado como fertilizante na cultura da soja, porém a quantidade de $\mathrm{N}$ presente neste composto pode inibir o processo de fixação biológica, interferindo também na produtividade da cultura, além de representar custos elevados aos produtores. Em virtude disso, o objetivo do presente trabalho foi avaliar o efeito de diferentes doses de $\mathrm{N}$ sobre a nodulação da soja, seu crescimento vegetativo e produção de biomassa.

\section{MATERIAL E MÉTODOS}

O experimento foi desenvolvido em casa de vegetação da Área de Ciência do Solo, Universidade Federal Rural da Amazônia - Belém, as coordenadas geográficas do local do experimento são $48^{\circ} 26^{\prime} 07^{\prime \prime} W$ e $1^{\circ} 27^{\prime} 07^{\prime \prime} S$. A classificação climática da região é Af segundo Koppen e Geiger e temperatura média de $26,5^{\circ} \mathrm{C}$. Utilizou-se como substrato Latossolo Amarelo, textura argilosa, da camada de 0-20 $\mathrm{cm}$, proveniente da cidade de Paragominas, PA. O solo foi peneirado em malha de 4 $\mathrm{mm}$ de diâmetro e distribuído em vasos com capacidade para aproximadamente 5 quilos de solo. Realizou-se análise de capacidade de campo e análise química do solo.

Foram utilizadas diferentes doses de nitrogênio, via solução nutritiva de cloreto de amônio $\left(\mathrm{NH}_{4} \mathrm{Cl}\right)$. As doses utilizadas foram de $100,75,50$ e $25 \mathrm{mg}$ de $\mathrm{N} / \mathrm{kg}$ de solo, totalizando 4 tratamentos e 5 repetições, sendo 20 vasos de $5 \mathrm{~kg}$ de solo cada, perfazendo 20 unidades experimentais. $O$ fósforo foi fornecido através de solução nutritiva de Ácido Fosfórico $\left(\mathrm{H}_{2} \mathrm{PO}_{4}\right)$ na dose $300 \mathrm{mg} / \mathrm{kg}$ solo. De acordo com análise química do solo não foi necessário adubação potássica. O molibdênio (Mo) foi fornecido na dose de $0,15 \mathrm{mg} / \mathrm{kg}$.solo via solução nutritiva de Óxido de molibdênio 
$\left(\mathrm{MoO}_{3) \text {. }}\right.$ (NOVAIS et al.,1991). As soluções nutritivas foram aplicadas sete dias após emergência (DAE).

O solo foi mantido a $80 \%$ da capacidade de campo desde o semeio até o fim do experimento. O semeio foi realizado com sementes da cultivar M 8644 I PRO, as quais foram inoculadas com inoculante Masterfix ${ }^{\circledR}$. A coleta de dados foi feita aos 22 DAE (estádio V4) e 39 DAE, no estádio R2 (florescimento pleno), ápice da formação de nódulos nas raízes e de absorção de $\mathrm{N}$, respectivamente.

No estádio V4 avaliou-se apenas variáveis de crescimento: altura da planta e diâmetro do caule. As variáveis avaliadas no estádio R2 foram: a avaliação do efeito das doses de nitrogênio na nodulação (contagem do número de nódulos e peso de nódulos), altura e diâmetro do caule e biomassa. Os resultados foram submetidos à análise de variância pelo Software Assistat ${ }^{\circledR}$. Utilizou-se o Teste Tukey a $5 \%$ de probabilidade.

\section{RESULTADOS E DISCUSSÃO}

\section{Quantidade e peso dos nódulos}

A interação entre as diferentes doses de nitrogênio e a nodulação (quantidade de nódulos e peso de nódulos) foi significativa. A quantidade de nódulos diferiu da maior dose (100 mg/kg.solo) para as demais doses e o peso dos nódulos diferiu entre todas as doses aplicadas.

Tanto a quantidade, quanto o peso de nódulos, foram maiores nas menores doses de nitrogênio aplicadas, porém as doses 25,50 e $75 \mathrm{mg} . \mathrm{kg}$ não diferem entre si na quantidade de nódulos e as doses $75 \mathrm{mg} . \mathrm{kg}$ e $100 \mathrm{mg} . \mathrm{kg}$ não diferem estatisticamente entre si ao analisar o peso dos nódulos, como pode ser observado nas Figuras 1 e 2, a seguir.

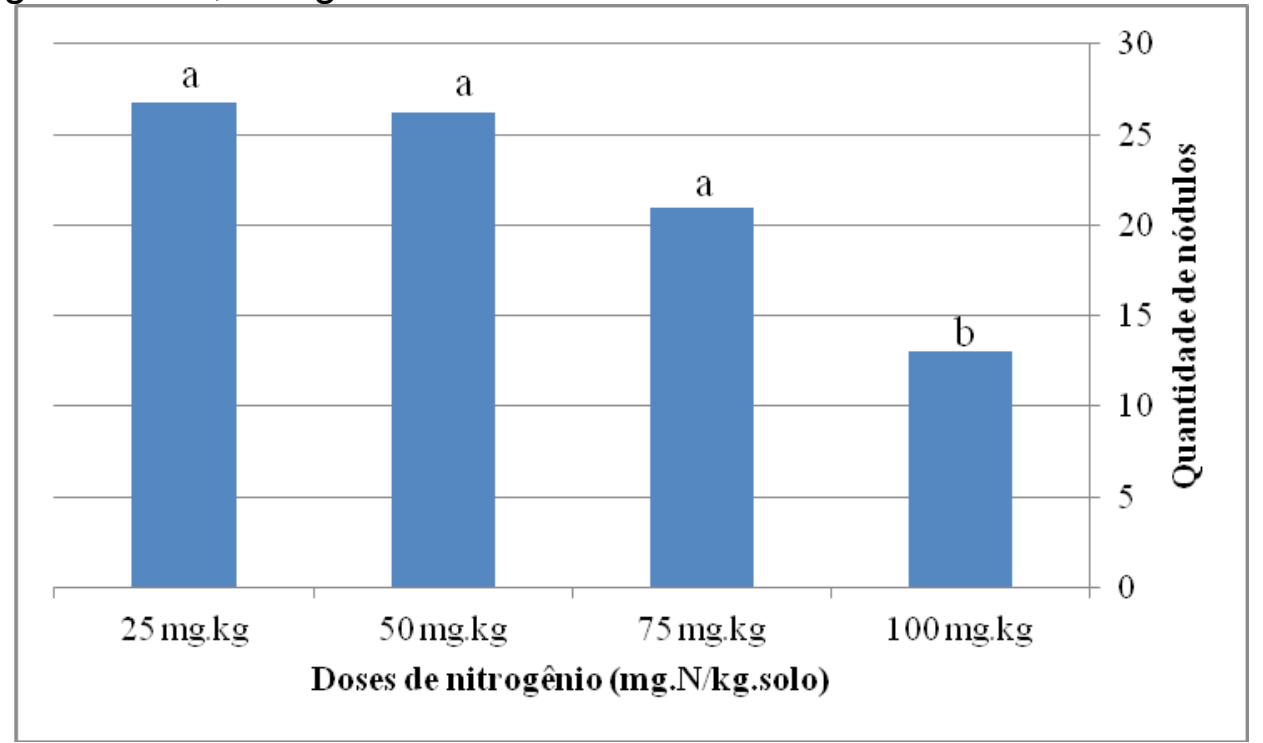

FIGURA 1. Quantidade de nódulos por vaso em função de diferentes doses de $\mathrm{N}$ por quilo de solo 


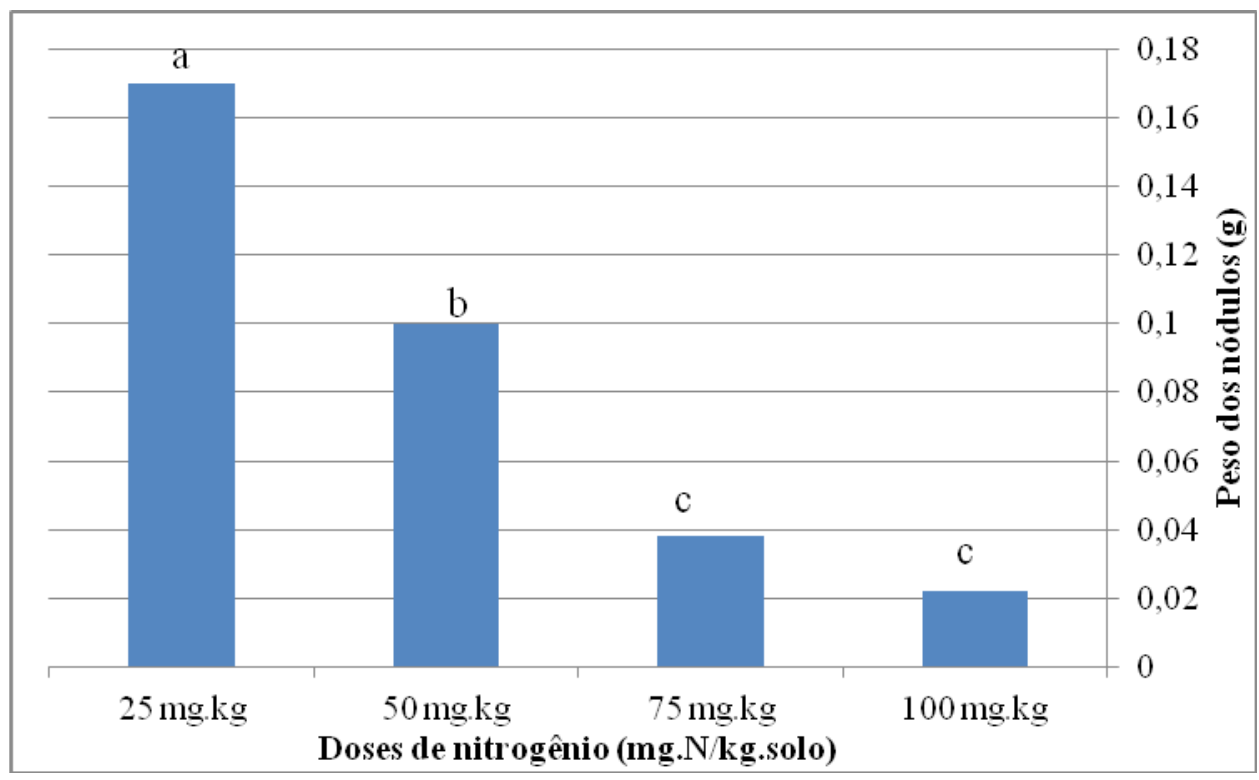

FIGURA 2. Peso dos nódulos em gramas em função das doses de $\mathrm{N}$ por quilo de solo

As altas doses de $\mathrm{N}$ fornecido inibiram a fixação biológica, semelhante ao observado por Yagi et al.. (2015) ao testarem o efeito da aplicação de fertilizante nitrogenado e inoculante com Rhizobium freirei sob diferentes cultivares de feijão (leguminosas que realizam fixação biológica do $\mathrm{N}$ similarmente à cultura da soja), onde notou-se redução significativa da quantidade de nódulos nos tratamentos em que foi aplicado $\mathrm{N}$.

Os resultados descritos nas Figuras 1 e 2 podem ser justificados por Brady e weil (2013), que afirmam que altos níveis de nitrogênio disponível, seja os do solo ou a ele adicionados em formas de adubos, tendem a reduzir a fixação biológica de nitrogênio, pois as plantas fazem investimento na energia exigida para a fixação simbiótica de nitrogênio, mas apenas quando a suplementação de $\mathrm{N}$ está reduzida, o que faz com que isso seja necessário.

Döbereiner e Arruda (1967) verificaram que altas doses de $\mathrm{N}$ aplicadas em diferentes variedades de soja reduziram o peso dos nódulos, semelhante ao apresentado na Figura 2, entretanto no caso do experimento dos autores, as doses mais altas de nitrogênio proporcionaram maior peso das plantas.

\section{Altura e diâmetro do caule no estádio V4}

O diâmetro do caule de plantas de soja no estádio V4 não variou entre os diferentes tratamentos a que foram submetidos, desta forma as diferentes doses de Nitrogênio não interferem no tamanho do diâmetro do caule no estádio vegetativo da soja (Figura 3). 


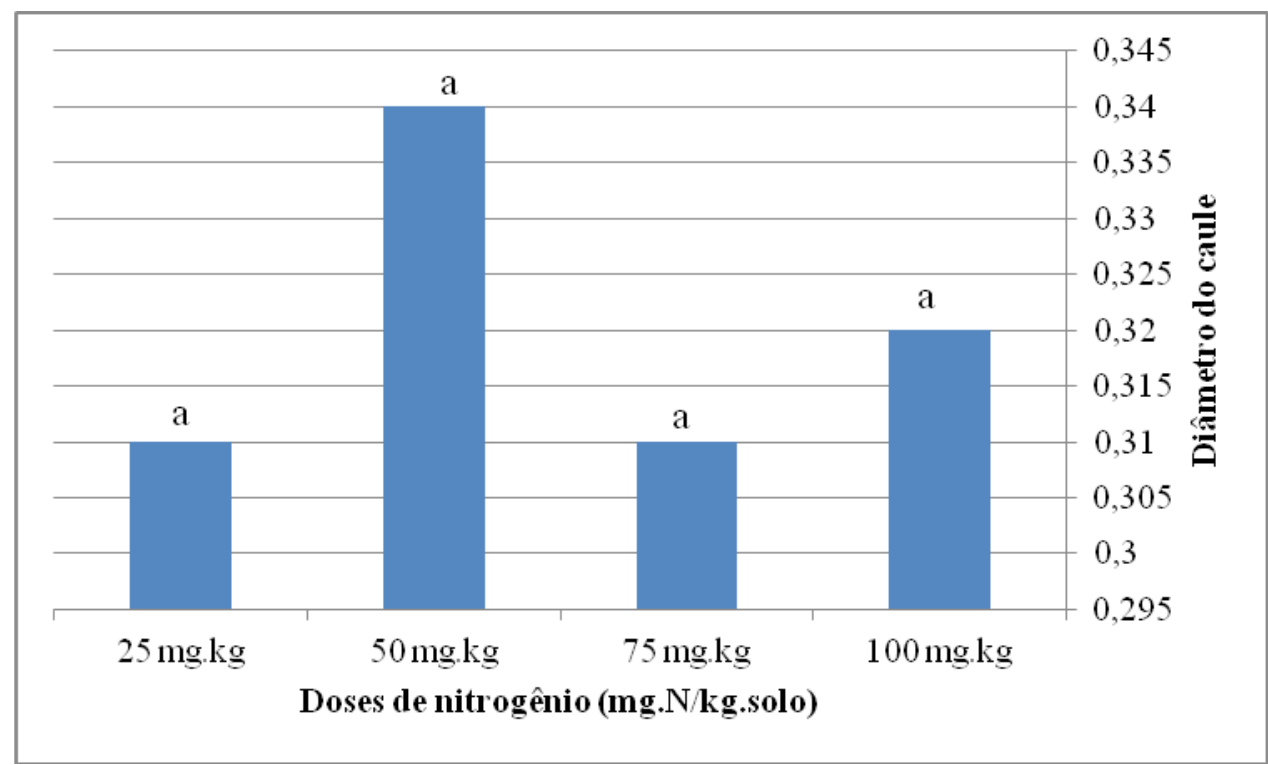

FIGURA 3. Diâmetro do caule em função das doses de N por quilo de solo

Em relação à altura das plantas, diferentes doses de $\mathrm{N}$ não apresentaram influência significativa aos 20 DAE (Figura 4). No estádio V4 o teor de N acumulado na planta é menor que 20\%. (OLIVEIRA JR et al., 2016) A absorção de N na cultura da soja é maior a partir do estádio R3 (OLIVEIRA JR et al., 2016), o que sugere que no estádio reprodutivo, diferentes doses de $\mathrm{N}$ podem afetar o diâmetro do caule $\mathrm{e}$ altura das plantas, diferente do observado neste experimento.

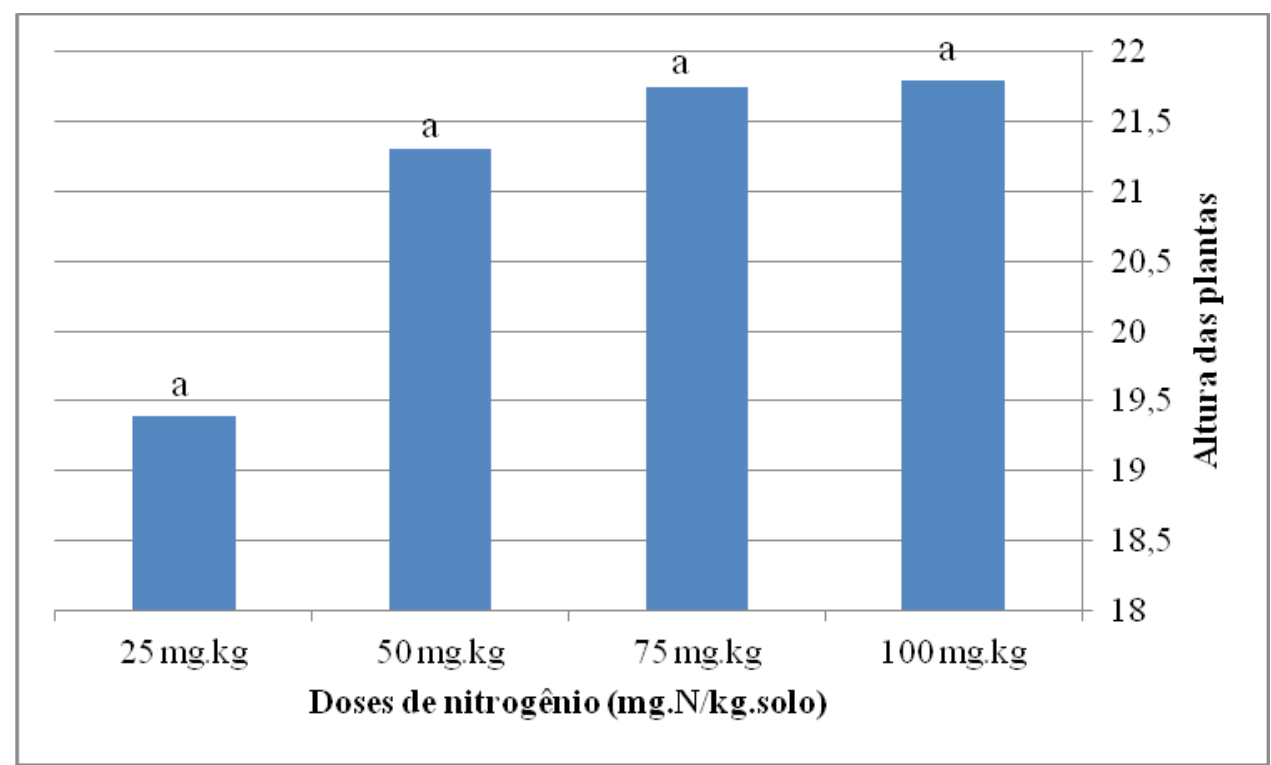

FIGURA 4. Altura das plantas no estádio V4 em função das doses de $\mathrm{N}$ por quilo de solo

\section{Altura e diâmetro do caule no estádio R2}

Não houve efeito significativo entre as doses de nitrogênio e a altura das plantas no estádio reprodutivo (Figura 5). 


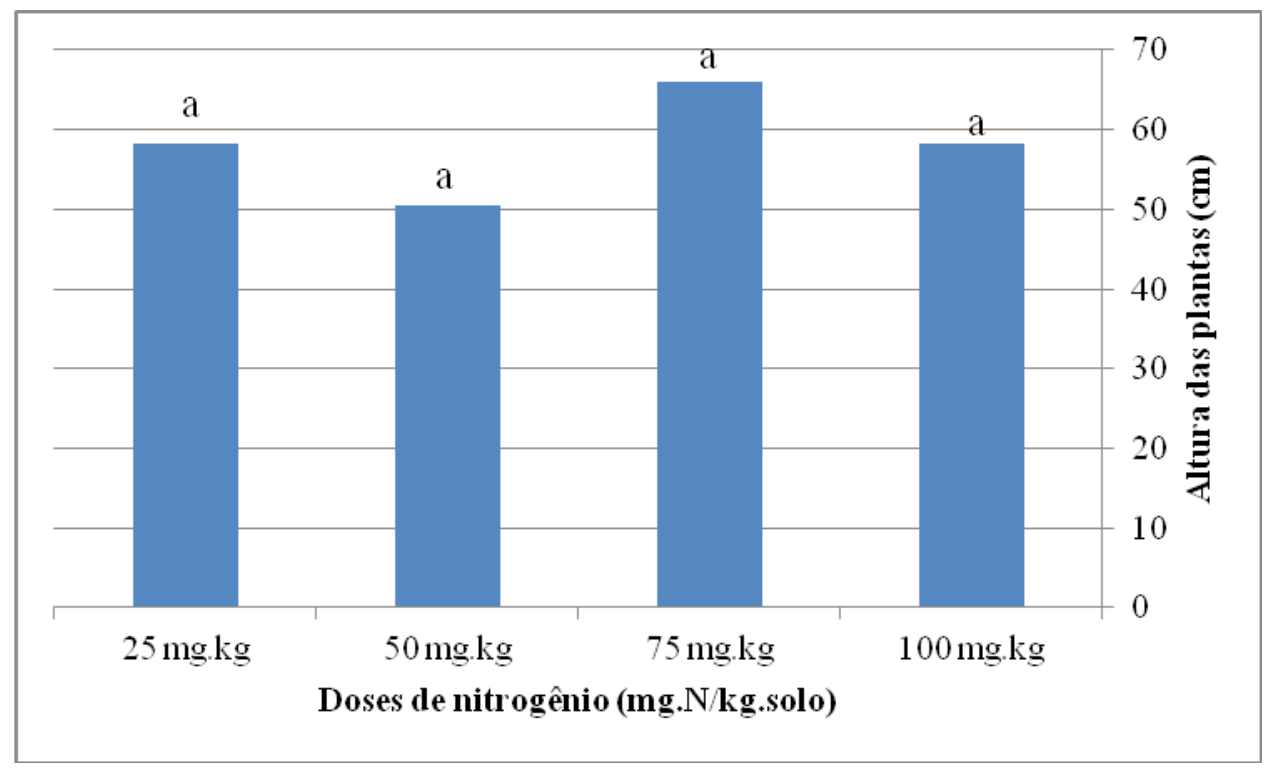

FIGURA 5. Altura das plantas em função das doses de $\mathrm{N}$ por quilo de solo

Quanto ao diâmetro do caule houve diferença significativa, onde os maiores diâmetros foram encontrados na maior dose aplicada, o que pode ser relacionado a um dos principais sintomas de deficiência de nitrogênio, que é a redução do diâmetro do caule e maior fragilidade dos mesmos (Figura 6)

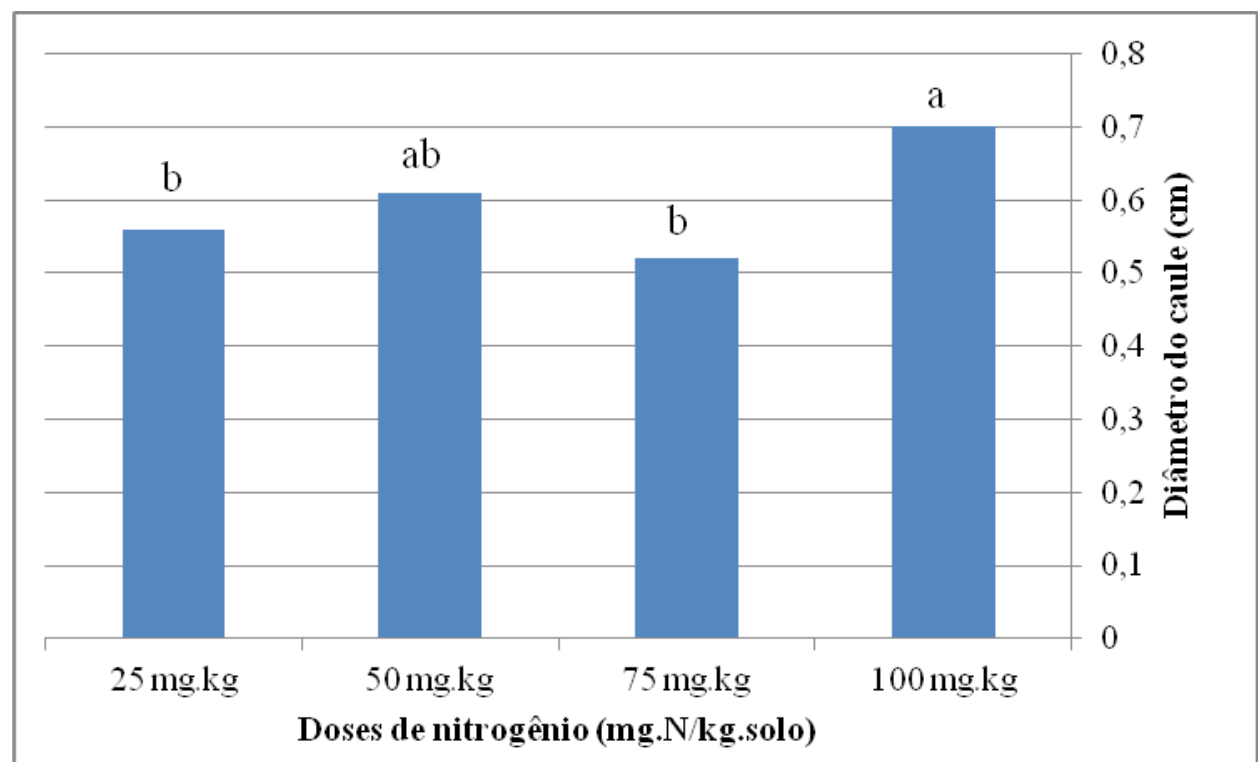

FIGURA 6. Diâmetro do caule em função das doses de $\mathrm{N}$ por quilo de solo

\section{Biomassa: matéria seca de folhas, hastes e raízes}

Diferentemente da produção de nódulos, as maiores doses de $\mathrm{N}$ apresentaram maior produção de biomassa seca na parte aérea (Figura 7 e 8), isto porque, de acordo com Epstein e Bloom (2006) a absorção de nutrientes afeta diretamente a taxa de crescimento das plantas. Porém, a produção de massa seca das raízes não teve diferença significativa entre os tratamentos, fator que indica que a redução na aplicação de $\mathrm{N}$ não influencia diretamente a produtividade da cultura (Figura 9). 


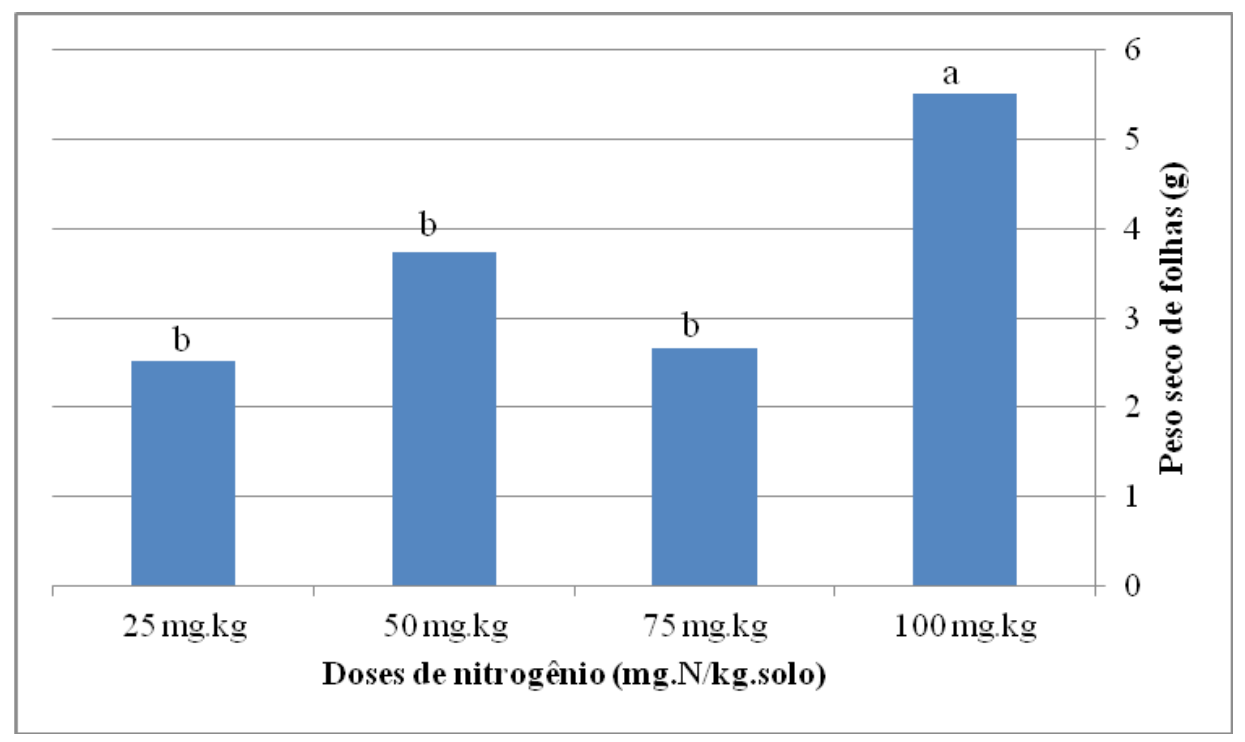

FIGURA 7. Peso de matéria seca de folhas em função de doses crescente de N

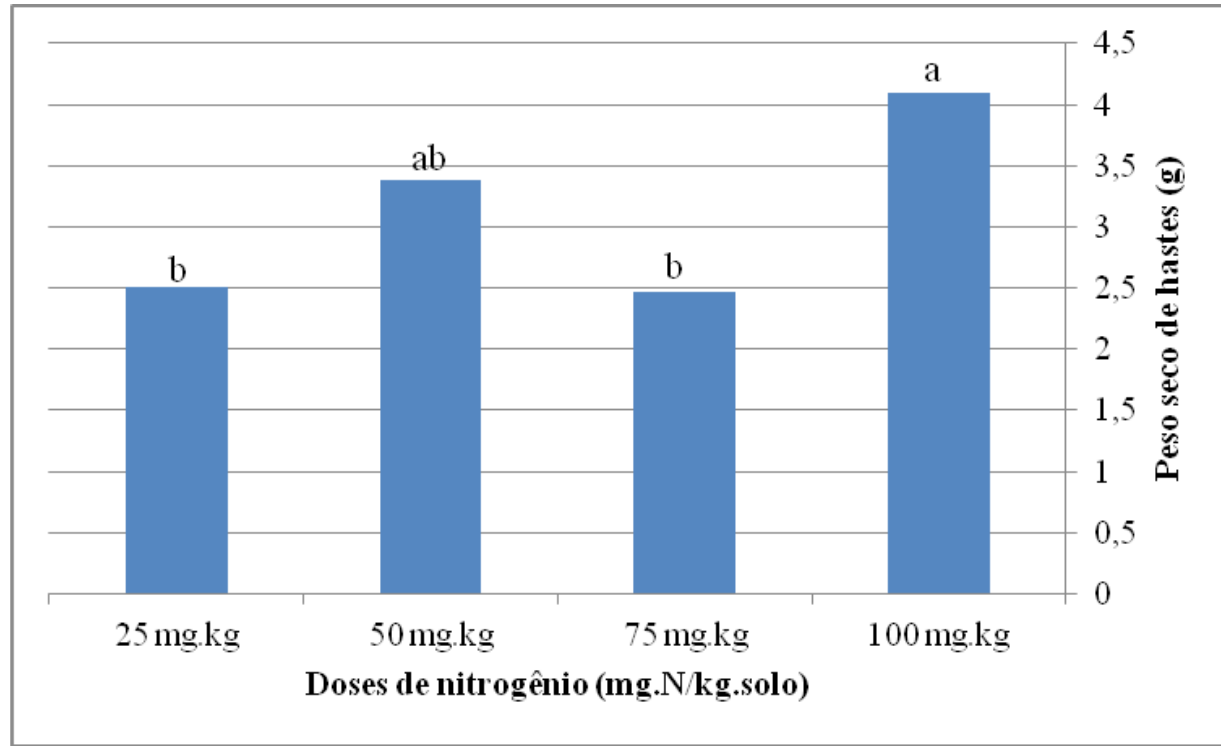

FIGURA 8. Peso de matéria seca de hastes em função de doses crescente de N

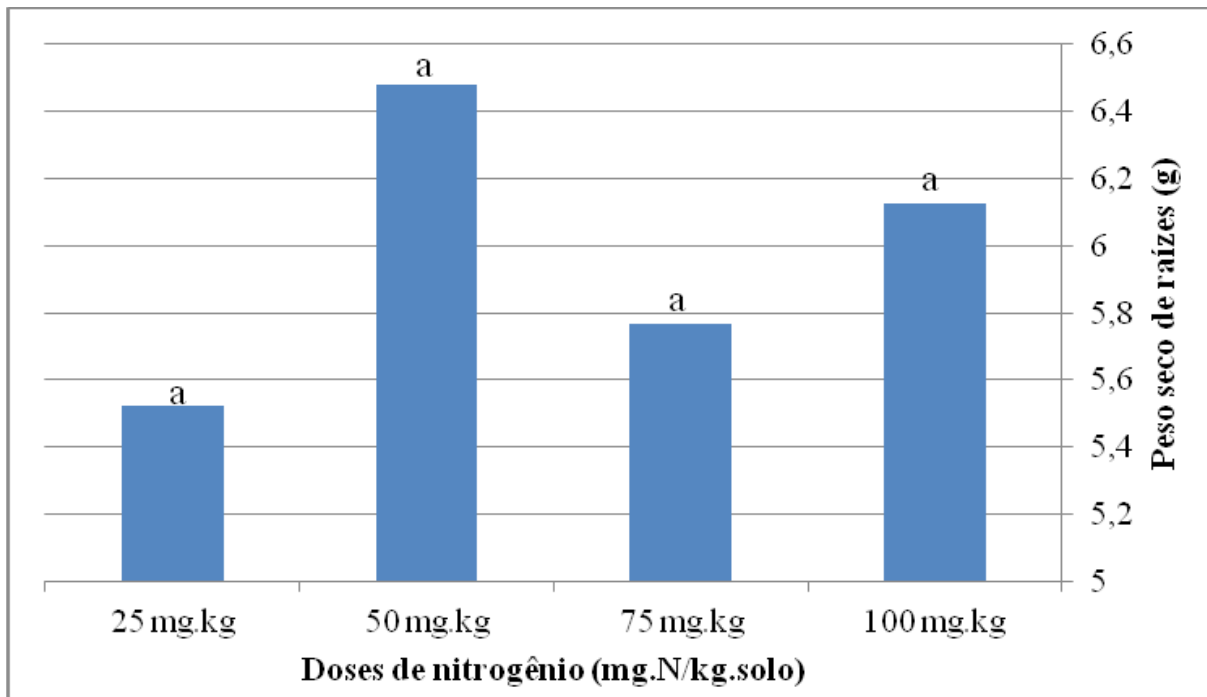

FIGURA 9. Peso de matéria seca de raízes em função de doses crescente de $\mathrm{N}$ ENCICLOPÉDIA BIOSFERA, Centro Científico Conhecer - Goiânia, v.15 n.27; p. 1852018 


\section{CONCLUSÃO}

A adubação nitrogenada não influencia diretamente no crescimento $\mathrm{e}$ produção de biomassa da cultura da soja, tanto no estado vegetativo, quando no estado reprodutivo. Entretanto, os resultados obtidos na análise de nodulação apresentaram diferença significativa entre os tratamentos utilizados, indicando redução no peso e quantidade dos nódulos quando ocorre excessiva aplicação de nitrogênio $(\mathrm{N})$. Isto comprova que a aplicação de $\mathrm{N}$ mineral representa alto custo à empresas produtoras de soja sem trazer maiores benefícios às plantas.

\section{AGRADECIMENTOS}

À empresa Juparanã pela concessão de insumos e acompanhamento técnico.

À Fundação Amazônia Paraense de Amparo à Pesquisa - FAPESPA pela concessão de bolsa de iniciação científica.

\section{REFERÊNCIAS}

BRADY, N. C.; WEIL, R. R. Elementos da natureza e propriedades dos solos. 3 ed. Porto Alegre: Bookman. 2013

CABALLERO, S. S. U. O nitrogênio e as plantas. Embrapa Soja. 2015. Disponível em:<http://www.agencia.cnptia.embrapa.br/gestor/canadeacucar/arvore/CONTAG01 31_711200516717.html>

CRAVO, M. S.; VIÉGAS, I. J. M.; BRASIL, E. C. Recomendações de Adubação e Calagem para o Estado do Pará. 1 ed. rev. atual. Belém: Embrapa. 2010.

DÖBEREINER, J; ARRUDA, N. B. Interrelações entre variedades e nutrição na nodulação e simbiose da soja (Glycine max (L.) Merril). Pesquisa Agropecuária Brasileira. $\quad$ p. 475-487. 1967. Disponível em: < https://seer.sct.embrapa.br/index.php/pab/article/viewFile/17964/12034>

EPSTEIN, E.; BLOOM, A. Nutrição mineral de plantas: princípios e perspectivas. 2 ed. Londrina: Editora Planta. 2006

NOVAIS, R. F.; NEVES, J. C. L.; BARROS, N. F. Ensaio em ambiente controlado. In: OLIVEIRA, A. J. 1991

OLIVEIRA JR, A.; CASTRO, C.; PEREIRA, L. R.; DOMINGOS, C. S. Estádios fenológicos e marcha de absorção de nutrientes da soja. 2016. Disponível em: < https://www.embrapa.br/soja/busca-de-publicacoes/-/publicacao/1047123/estadiosfenologicos-e-marcha-de-absorcao-de-nutrientes-da-soja>

SFREDO, G. J. Soja no Brasil: Calagem, adubação e nutrição mineral. Londrina: Embrapa Soja, 2008. 148 p. (Embrapa Soja. Documentos 305). Disponível em: < http://www.cnpso.embrapa.br/download/Doc305.pdf>

SIDRA - Sistema Ibge de Recuperação automática. Produção agrícola municipal. 2018. Disponível em: <https://sidra.ibge.gov.br/home/lspa/brasil> Acesso em: 12 de março de 2018. 
YAGI, R.; ANDRADE, D. S.; WAURECK, A.; GOMES, J. C. Nodulações e produtividades de grãos de feijoeiros diante da adubação nitrogenada ou da inoculação com Rhyzobium freirei. Revista Brasileira de Ciência do Solo. 39: 1661-1670. 2015. Disponível em: < http://www.scielo.br/pdf/rbcs/v39n6/0100-0683rbcs-39-6-1661.pdf> doi: 10.1590/01000683rbcs20140342

USDA - UNITED STATES DEPARTMENT OF AGRICULTURE. World Agricultural Supply and Demand Estimates. 2017. 40 p. Disponível em: < https://www.usda.gov/oce/commodity/wasde/latest.pdf> 